\title{
NEW PRODUCT SUCCESS: THE ROLE OF SERIAL INNOVATORS FOR TIME-TO-MARKET
}

\author{
Eunsang Yoon, University of Massachusetts Lowell, U.S.A.
}

\author{
dx.doi.org/10.18374/IJBR-20-1.4
}

\begin{abstract}
One of the management goals through the process of product innovation is speeding up the completion of concept generation/evaluation, design/development, and testing/programming for its timely market entry. The literature report various strategic supports for the acceleration of Time-to-Market of a new product, e.g. efficiently organizing a dedicated cross-functional team, collaboratively intensifying the resource commitment, proactively shortening the process of designing and prototyping, timely securing the capacity for manufacturing, and synergistically coordinating the marketing programs. The role and contribution of serial innovators is often essential to accomplish the complex tasks of timely developing and launching a new product, especially in many cases of radical innovation. The serial innovator's capacity of bridging the gap between technology and market is based on their confidence and ability of understanding the customer's problems and competitive environment, discovering the technical solutions, confirming the customer acceptance, and estimating the market potential of the new product. This study examines a qualitative decision of launching a new product into the market as a pioneer or follower and explores the strategic implications of a case study on the new product success factors in relation to the role of serial innovators. The lessons from sixty pioneering and following market-entry cases confirm such success-factors as: Technical or technological superiority, Competitive advantages associated with the market-entry time, Enhanced customer service, Appeal to the customers with additional value, Superior quality of the product offering, Expanding industry and market demand, Cost or pricing advantages, Intelligence advantages, Brand identity or customer loyalty, and Partnership or leadership advantages. Many of these success factors are common to pioneers and followers and closely related to the capacity of the serial innovators having expertise in both science and business.
\end{abstract}

Keywords: product, serial innovation, time-to-market 